\title{
artículos
}

\section{A Different Kind Of Tension. Discursos artísticos, marginales y musicales en las escenas del punk}

\author{
Isabel María Guerrero Aparicio \\ Investigadora vinculada a la UMA
}

RESUMEN

Las diferentes escenas del punk, que de Estados Unidos y Gran Bretaña se exportaron al resto del mundo, se gestaron en un espacio textual compuesto por clubes, tiendas de moda y locales de ensayo, facultades de Arte y cafés, fanzines y revistas musicales, discográficas y sellos independientes. El siguiente trabajo, que forma parte de una obra más amplia que estudia los discursos artísticos, marginales y musicales del punk, se centra en estos espacios de libertad, deudores de todo tipo de prácticas autónomas y alternativas, nihilistas y defensoras de lo amateur, que a su vez contaminaron las corrientes artísticas de finales de los setenta.

PALABRAS CLAVE: Punk/ Subculturas/ Amateurismo/ Escena musical/ Arte emancipatorio/ Performance.

A Different Kind Of Tension. Artistic, marginal and musical discourses in scenes of Punk

ABSTRACT

The different punk scenes, exported from USA and UK to the rest of the world, originated in a contextual mixture of clubs, fashion shops and rehearsal rooms, art colleges and coffee shops, fanzines and music magazines, record companies and independent record labels. The present study, stemming from a wider work on artistic, marginal and musical perspectives of punk, is focused on these spaces of freedom that owe all kinds of autonomous and alternative practices. These nihilistic and amateur-loving influences also contaminated the artistic movements from the end of the 70 s.

KEY WORDS: Punk/ Subcultures/ Amateurism/ Musical scene/ Emancipatory art/ performance.

"Mi vida cambió en el momento en que vi a los Sex Pistols. Inmediatamente me di cuenta de que tenía que intentar que algo pasara"1, dijo Howard Devoto. Una especie de "llamada" (wake-up call) fue lo que sintió Steve Diggle, quien simplemente no había escuchado nada igual en su vida ${ }^{2}$. Como si de una vocación religiosa se tratara, la llamada surtió efecto: habían nacido los Buzzcocks. Peter MacNeish (Pete Shelley) y Howard Trafford (Howard Devoto) eran en aquella época estudiantes de

* GUERRERO APARICIO, Isabel María: "A Different Kind Of Tension. Discursos artísticos, marginales y musicales en las escenas del punk", en Boletín de Arte $n^{\circ} 32-33$, Departamento de Historia del Arte, Universidad de Málaga, 2011-2012, págs. 323-330. Fecha de recepción: Junio de 2011.

1 Citado en ALBIEZ, Sean, "Print the truth, not the legend. The Sex Pistols: Lesser Free Trade Hall, Manchester June 4, 1976", en VV.AA., Performance and Popular Music: History, Place and Time, Brookfield, VT, USA, Ashgate Publishing Company, 2006, p. 102.

2 Citado en ibídem, p. 102. 

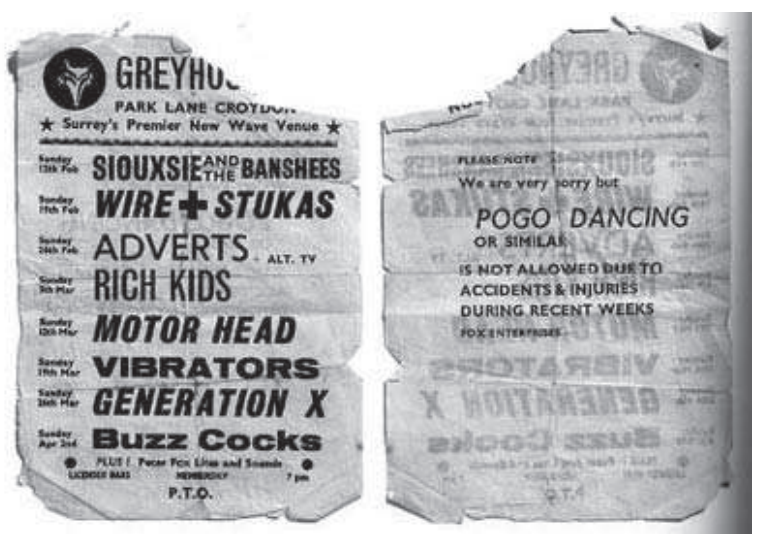

\begin{tabular}{l}
\hline 1. Flyer con la \\
programación \\
Greyhound, en cuyo \\
reverso se puede ver un \\
curioso texto en el que se \\
prohíbe bailar pogo "o \\
similares".
\end{tabular}

Bolton. Cuando leyeron la crónica que Neil Spencer había escrito para el New Musical Express sobre unos primitivos Pistols y su actuación en el Marquee londinense, quedaron hechizados con el texto, que describía el directo de la banda como "una experiencia musical con énfasis en la Experiencia”, una 'experiencia' sobre sexo, violencia, insolencia y anarquía ${ }^{3}$. Spencer transcribió la confesión de uno de los miembros de la banda: "no estamos inmersos en la música... sino en el caos"4. Devoto y Shelley quisieron compartir la 'experiencia' de los Pistols con otros ${ }^{5}$, así que alquilaron el Lesser Free Trade Hall por 32 libras.

Manchester, 4 de junio de 1976. No más de un centenar de personas se acercaron a este pequeño teatro de la ciudad (Lesser Free Trade Hall) para asistir al que muchos consideran el 'acto fundacional' de la escena musical mancuniana (la que ha dado de sí nombres tan importantísimos para la música popular anglosajona como Joy Division o The Smiths, entre otros muchos). El debut de los Pistols se había producido anteriormente en una discoteca repleta de hooligans del Manchester United y el Manchester City. Posteriormente, dio paso al concierto del Lesser Free, en el que "hubo bastante público"6, a juzgar por lo que recuerda Lydon.

Michael Winterbottom reconstruyó el histórico concierto en su película 24 Hour Party People (2002), ficción que recrea la evolución de la escena musical en Manchester en boca del periodista, promotor y agitador musical Tony Wilson ${ }^{7}$. Wilson

\footnotetext{
3 Ibídem, p. 97.

4 Citado en ibídem, p. 97

5 Ibídem, p. 97.

6 Citado en LYDON, John, Rotten: No Irish, No Blacks, No Dogs. La autobiografía autorizada de Johnny Rotten, cantante de los Sex Pistols, Madrid, Acuarela, A. Machado Libros, 2007, p. 122.

7 Wilson es un personaje importantísimo en la cultura pop británica y, por ende, internacional. Fue uno de los fundadores de Factory Records (el sello que publicó los trabajos de Joy Division, New Order y Happy Mondays, entre otras bandas), así como el promotor del famoso club Haçienda (Manchester). En la escena mancuniana,
} 
2. Man Ray, fundador del dadá neoyorquino junto con Duchamp y Francis Picabia.

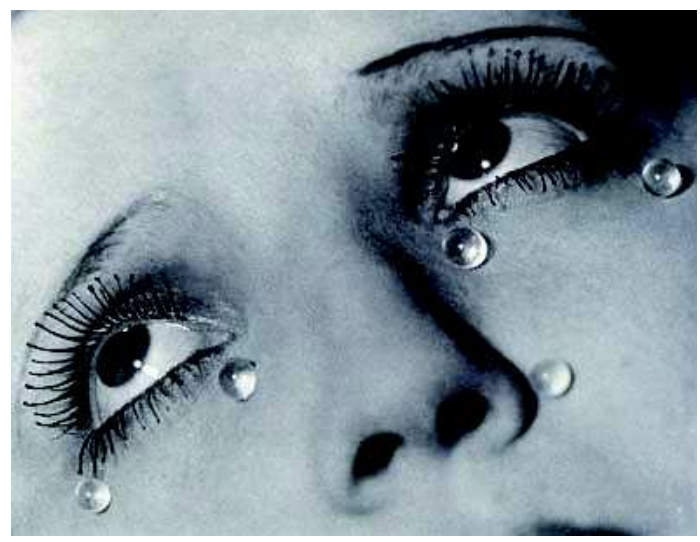

hace gala de la máxima "entre la verdad y la leyenda, quédate con la leyenda", de ahí que, con respecto a lo que cuenta el documental de David Nolan I Swear I Was There (Granada TV, 2001) acerca del mismo acontecimiento, haya diferencias notables en cuanto a presencias destacables en ese concierto. Al parecer, según crónicas fiables, puede decirse que se encontraban allí Pete Shelley, Howard Devoto y Steve Diggle (quienes formarían los primeros Buzzcocks); Bernard Sumner y Peter Hook (Joy Division y, después, New Order); Paul Morley (a la postre, autor y periodista musical); Morrissey (The Smiths); Malcolm McLaren y Jordan (empleada en la boutique, Sex, creadora de tendencias y mánager de Adam and The Ants); la banda telonera, Solstice; Eddie Garrity (más tarde, en Ed Banger and The Nosebleeds); lan Moss (quien formó grupo con Mick Hucknall, Frantic Elevators); y John the Postman ${ }^{8}$, figura omnipresente de la escena punk y post-punk mancuniana9. Sean Albiez incide en la importancia de un capítulo que contribuyó a inspirar la salida de Spiral Scratch, el EP auto editado por los Buzzcocks en febrero de $1977^{10}$.

Así, la atomización que existía a principios de los setenta dio paso a la materialización de las subculturas del punk, fenómeno que se desarrolló y escenificó en determinados espacios textuales, como indica Juan Carlos Fernández Serrato ${ }^{11}$. Individuos aislados en sus edificios de viviendas protegidas o en barrios periféricos, en el caso de Inglaterra, cuando no en zonas residenciales y otros núcleos urbanos, en el caso de Estados Unidos, confluyeron en salas y locales de ensayo, facultades

conocida como Madchester, predominaron especialmente sonidos relacionados con el rock psicodélico, el indie y la música electrónica de la época.

8 En español, John "el Cartero".

9 ALBIEZ, Sean, op. cit., p. 93.

10 Ibídem, p. 94

11 FERNÁNDEZ SERRATO, Juan Carlos, "Márgenes de la estética y estéticas al margen". Gittcus, Publicación digital del grupo de investigación en teoría y tecnología de la comunicación de la Universidad de Sevilla, p. 2.

Disponible en web: http://huespedes.cica.es/aliens/gittcus/serrato11.htm. 


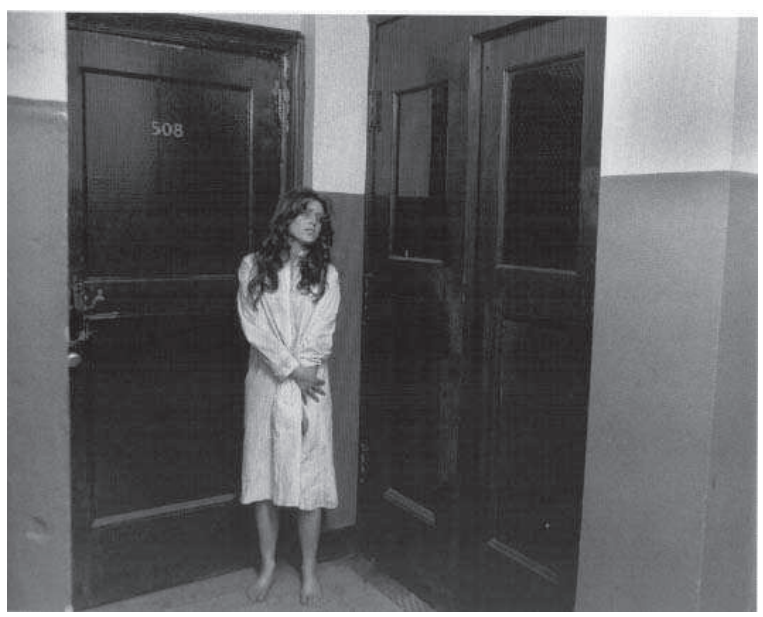

3. Cindy Sherman
comienza sus conocidas
Untitled Film Stills en
1977 (en la imagen, Film
Still \#28).

y cafés, en las tiendas, en las calles. Primero fueron artistas y jóvenes aislados, después, pasarían a formar parte de una vanguardia que se tornó movimiento ${ }^{12}$. Con la realidad virtual aún muy lejana, éstos eran los espacios físicos en los que la actividad artística se producía y se confundía con la vida. Estos espacios eran imprescindibles, así como los medios que propiciaron la difusión de esta cultura (fanzines y revistas, discográficas y sellos pequeños).

El punk creó su propio espacio de libertad en los márgenes, o en las alcantarillas, de los canales del pop oficial, y se encontró con un espacio de subsistencia, una gran voluntad de conmoción, la respuesta de un público marginal y entregado ${ }^{13}$, necesitado de encontrar nuevas identidades en tiempo de subsistencia. El viejo sueño de "sembrar el mundo de personas autónomas"14, de creadores indiferentes (en la más estricta tradición del situacionismo y del dadaísmo) reaparecía en su enésimo intento. Dentro del panorama que Marcus nos pinta a principios del siglo XX, y que comienza por lo que él denomina genéricamente "el hundimiento del arte del ayer", a saber: la reducción de las formas a cero (De Stijl, el expresionismo abstracto), la yuxtaposición de fenómenos aparentemente inconexos (dadaísmo), y la retirada desesperada de esas utopías ${ }^{15}$. La posmodernidad trae consigo el desencanto, las ansias de emancipación decaen cuando el arte de las vanguardias entra en el museo y en el mercado ${ }^{16}$.

12 CHRISTGAU, Robert, "A Cult Explodes... and a Movement Is Born", en Village Voice, Nueva York, 1977 p. 2. Disponible en web: http://www.robertchristgau.com/xg/music/avantpunk-77.php.

13 MARCUS, Greil, Rastros de carmín, Barcelona, Anagrama, 1993, p. 85

14 Citado en ibídem, p. 329.

15 Ibídem, p. 202.

16 VIDAL i AULADELL, Felip, “Arte posmoderno y emancipación”, en A Parte Rei, 23, 2002, p. 2. 
4. Imágenes de Prostitution, COUM Transmissions, Instituto de Arte Contemporáneo de Londres (1976).

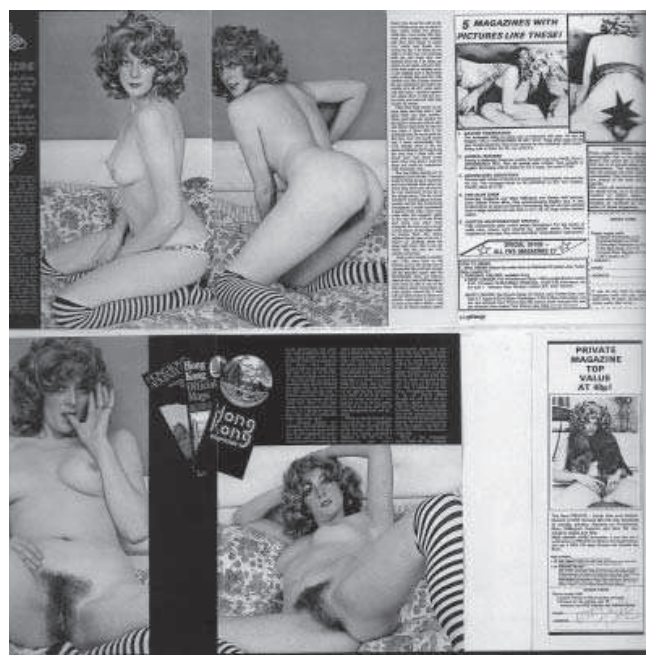

A la manera de Marcel Duchamp, el punk rock reutilizó objetos propios de la vida cotidiana para definir su estilo e indumentaria ${ }^{17}$, ensalzó el concepto de desecho en una sociedad capitalista que empezaba a acusar todo tipo de miserias. Convirtió al cuerpo en una especie de escultura, susceptible de auto lesión, cuando no en un boceto sobre el que volcar cualquier ansia expresiva.

Si la práctica musical es lo que Deleuze y Guattari denominan "literatura menor"18, a saber, "aquella que una minoría hace dentro de una lengua establecida"19 debemos reconocerle a este lenguaje minoritario la capacidad de haber construido una retórica seductora para determinadas corrientes vanguardistas de la época. Éstas encontraron "un camino inédito y un espacio textual abierto que permitieron su renovación al margen de los circuitos y sistemas de convenciones que controlan lo que llamamos arte"20. Cuesta, quizá, admitirlo (al menos en un nivel teórico), teniendo en cuenta que la música es, junto con el cine, una disciplina en la que el canon artístico actual dirime aún dónde están los límites ${ }^{21}$. El lugar del arte ${ }^{22}$ ha sido y es objeto de discusión, sobre todo desde finales del siglo pasado, cuando los discursos empiezan a precisar ya de tecnología pura y dura y la frontera estética se antoja difusa.

17 ROCHA, Servando, Agotados de esperar el fin. Subculturas, estéticas y políticas del desecho, Virus Editorial, 2008, p. 2.

18 Citado en ACINAS VÁZQUEZ, Juan Claudio, Crisis civilizatoria y marginalidad: un estudio del movimiento "punk", Tenerife, Universidad de La Laguna, Secretariado de publicaciones, 1987, p. 27.

19 Citado en ibídem, p. 28.

20 FERNÁNDEZ SERRATO, J. C., art. cit., p. 2.

21 FERÁNDEZ SERRATO, J. C., art. cit., p. 2.

22 Ibídem, p. 2 
La interpretación de la escritura que realizan Derrida y Barthes, que pasa por ser verbal, visual, gestual o musical, contribuye a densificar el lenguaje ${ }^{23}$. Como "espacio de la libertad", la escritura "encarna un conflicto que vive justamente de su constante insatisfacción, de un deseo no funcional y no remediable"24. El espacio textual en el que se desarrolló el punk contribuyó "durante un tiempo, como por arte de magia [...] a que el movimiento tuviese voz propia, y funcionaste como un nuevo tipo de libertad de expresión"25. "Pocos momentos de la música popular alcanzan el grado del grito gutural de Rotten" cuando, al final de God Save The Queen, canta aquel verso ("No future for you"), que tan bien resume todos aquellos años de penurias juveniles y frustraciones ${ }^{26}$.

Como suele decirse, menos puede llegar a ser más. $Y$ en el caso del punk partimos de una negatividad que, en un contexto en el que "la dominación se postula como principio"27, estalló en una liberación para la cual el arte popular fue el mejor vehículo. Según Marcus, el punk jugaba a la dialéctica negativa de Adorno, "en la que cada sí se convertía en un no"28. Pese a todo, los protagonistas de la escena londinense aseguran que no fue un período tan nihilista. "Creo que fue una época de mucha sinceridad"29, dice al respecto Steve Severin.

El punk dispuso de un estimulante y eficaz sistema alternativo de medios de comunicación. Los fanzines, la prensa musical, los cómics y la publicidad (pósters, pegatinas, flyers) que según J. Lotman "revelan un una concepción del mundo, unos valores admirados y (per)seguidos, y unos gustos que marcan profundamente la identidad de un individuo, máxima si pertenece de forma intensa a un grupo y si ese grupo profesa una ideología, o una conducta o actitud que se puede definir como antisocial" ${ }^{30}$.

En el caso inglés, el aumento del número de bandas amateur, siguiendo la estela de los Sex Pistols, espoleó precisamente el crecimiento de todo el universo que rodeaba el ambiente musical: sellos discográficos, fanzines, locales, salas como el 100 Club $^{31}$, donde los Sex Pistols empezaron a tocar regularmente en marzo de 1976. "En los años siguientes había más de quince mil grupos grabando discos"32, especialmente motivados ante la posibilidad de tocar en escenarios como aquel. Allí debutó también la banda de Sid, Siouxsie y Marco Pirroni (Flowers of Romance), en

23 MÉNDEZ RUBIO, Antonio, El conflicto entre lo popular y lo masivo, Centro de Semiótica y Teoría del Espectáculo, Universitat de Valencia y Asociación Vasca de Semiótica, Eutopías, vol. 85, Valencia 1995, p. 2. 24 Ibídem, p. 6.

25 MARCUS, G., op. cit., p. 10.

26 VV.AA.,1001 discos que hay que escuchar antes de morir, Barcelona, Grijalbo, 2005, p. 394

27 MARCUS, G., op. cit., p. 82

28 Ibídem, p. 87

29 Citado en LYDON, J., op. cit., p. 210.

30 COSTA, Pere-Oriol, PÉREZ TORNERO, José Manuel, TROPEA, Fabio; colaboración de Charo Lacalle Tribus urbanas. El ansia de identidad juvenil: entre el culto a la imagen y la autoafirmación a través de la violencia, Barcelona, Paidós, 1996, p. 23.

31 Fue en este espacio donde tuvo lugar el primer festival punk, el 20 de agosto de 1976.

32 MARCUS, G., op. cit., p. 74. 
una época de seguidores que aún carecían del "uniforme punk"33. Otros lugares de encuentro en aquellos días fueron el Roxy y el Louise's, un local de lesbianas. Steve Severin recuerda que "todo surgió de la escena gay" ${ }^{34}$. En este sentido, Chrissie Hynde destaca cómo la ausencia de sexismo o racismo que hubo en los comienzos convirtió al movimiento en algo bello: "a todo el mundo le encantaba el reggae y estaba mal visto juzgar la sexualidad de los demás”35.

Malcolm McLaren alquiló un pequeño cine del norte londinense llamado Screen on the Green. Allí tocaron los Pistols y las Slits con películas del cineasta queercore ${ }^{36}$ Kenneth Anger de fondo: "Se suponía que en las películas había un concepto perverso, pero con aquel ambiente resultaban ridículas y muy divertidas"37. En este sentido, una vez más, afloraba el sentido del humor de la escena londinense, en contraposición con la neoyorquina, donde por el contrario "se deleitaban con aquellas películas y las tomaban en serio, ubicándolas en un contexto artístico"38, según Johnny Rotten. No en vano, la sala era "la versión warholiana y nihilista de mediados de los sesenta, una extraña mezcla de ingenuidad y decadencia"39.

Lo trash o lo camp ${ }^{40}$ son conceptos inequívocamente contemporáneos de los que McLaren, ávido cazador, se nutrió considerablemente. Autores como Jordi Costa defienden el potencial liberador y la heterodoxia del fenómeno del mal gusto a nivel estético, al margen de sus trascendencias sociales y existenciales. Susan Sontag reflexiona sobre las experiencias de lo camp, "basadas en el gran descubrimiento de que la sensibilidad de la alta cultura no tiene el monopolio del refinamiento. El camp afirma que el buen gusto no es simplemente buen gusto; que existe, en realidad, un buen gusto del mal gusto"41. Es más, tampoco podemos olvidar, como denunciaba Barthes, que pese a "la apariencia democrática y apacible de la actual cultura de masas [ésta] procura una generalización del consumo que mantiene, sin embargo, divisiones y privilegios en el terreno de la participación creativa. La adopción y vulgarización de modelos burgueses tradicionales, así como la sumisión a los estereotipos y la inmovilidad ideológica, apoyada por el soporte estatalista, serían algunos de sus mecanismos fundamentales"42.

En este sentido, la confusión entre arte y vida que generó el punk influyó decisivamente en artistas contemporáneos. Como paradigma alocado para el body-

33 LYDON, J., op. cit., p. 125

34 Citado en ibídem, p. 204

35 Citado en ibídem, p. 182

36 Queercore, movimiento cultural y social gestado en a mediados de los ochenta, asume las formas del punk para rechazar el normatividad heterosexual y la cultura gay "establecida".

37 Citado en LYDON, J., op. cit., p. 128.

38 Citado en ibídem, p. 128.

39 SAVAGE, John, England's Dreaming. Los Sex Pistols y el punk rock, Reservoir Books-Mondadori, 2009, p. 273.

40 Estética basada en el mal gusto y en la ironía, se acerca al kitsch si bien no es exactamente lo mismo. Susan Sontag le dedicó uno de sus ensayos (Notas sobre lo camp).

41 Citado en CONDERANA, José Alberto, "Capitulaciones de la estética contemporánea I: el silencio como anomalía", en Trípodos, $\mathrm{n}^{\circ}$ 19, Barcelona, 2006, p. 177.

42 MÉNDEZ RUBIO, A., op. cit., p. 9. 
art, como referente en cuanto al culto al arte hecho por no artistas (utopía de los conceptuales), como happening constante en forma de conciertos, y como fenómeno popular y urbano que superaba el rock encorsetado para volver a cierto atavismo ${ }^{43}$. La necesidad puntual de la interdisciplinariedad de las artes, la unión entre la estética y la experiencia o el hecho de desacralizar lo artístico son presupuestos vanguardistas que conectan con "el texto-espectáculo" propio del rock ${ }^{44}$. La marginalidad es el espacio de lo inseguro y cambiante, de lo contradictorio y, por lo tanto, vivo ${ }^{45}$. La transitoriedad que, según Adorno, dota de contenido al propio arte ${ }^{46}$.

Prostitution (1976), en el Instituto de Arte Contemporáneo de Londres, se puede considerar retrospectivamente como uno de los primeros eventos punk a nivel artístico. El colectivo COUM Transmissions fue el responsable de la muestra, compuesta principalmente por performances de body-art y actuaciones del grupo de rock Throbbing Gristle que algunos consideraron pornográficas. Genesis P-Orridge (nacido Neil Megson, miembro de COUM) había trabajado con artistas posteriores al Fluxus, y creía en la ruptura de los tabúes a través del arte de la performance, así como en la necesidad de inducir una situación crítica en la que estar/sentirse vivo, y a su vez amenazado por la sociedad ${ }^{47}$. Prostitution causó un escándalo enorme, pero abrió la veda, de alguna manera, a un territorio "de rebelión estética frente a las sociedades posmodernas, donde el espectáculo integrado dicta sus modelos de comportamiento y pensamiento" 48 . Antes, dentro del ciclo "Fashion Forum - New Designers", Malcolm McLaren y Vivienne Westwood ya habían sido convocados para ofrecer una charla en el mismo escenario, el ICA, acerca del mestizaje entre moda, arte, antropología y cultura popular ${ }^{49}$ que tan asumido tenemos hoy en día.

El potencial emancipatorio del arte cuando se hace autónomo, según Adorno, se complementa con los usos emancipadores que la técnica puede llegar a tener, en opinión de Benjamin ${ }^{50}$. El movimiento punk fue capaz de apropiarse de ese deseo de emancipación, e incluso de abrir un espacio de confluencia con corrientes artísticas "situadas en el afuera del arte como mercancía" 51.

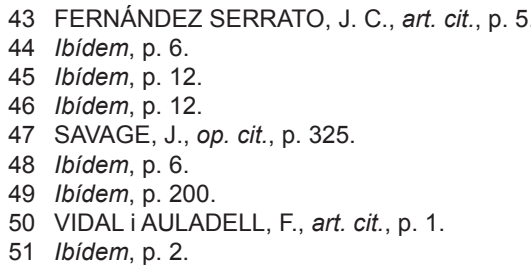

